\title{
Evaluation of bioactive glass and hydroxyapatite crystals as pulpotomy agents in primary molars: A clinical study
}

\author{
Neeraja Govindaraj ${ }^{1}$, (D) Kinjal Shah ${ }^{2}$, (D) Priya Subramaniam ${ }^{3}$, (D) Megha Gupta ${ }^{4} \bowtie$
}

\section{Highlights}

The pulp in the primary teeth has immense potential for repair because of a high degree of cellularity and vascularity in this tissue.

1 Former Reader

Department of Pedodontics and Preventive

Dentistry

The Oxford Dental College and Hospital

Bangalore, India

${ }^{2}$ Former Post graduate student

Department of Pedodontics and Preventive

Dentistry

The Oxford Dental College and Hospital

Bangalore, India.

${ }^{3}$ Professor and Head

Department of Pedodontics and Preventive Dentistry

The Oxford Dental College and Hospital

Bangalore, India

${ }^{4}$ Reader

Department of Pedodontics and Preventive

Dentistry

Vyas Dental college and Hospital

Jodhpur, India.

\section{Correspondence:}

Vyas Dental college and Hospital

Jodhpur, India.

E-mail address:

meghamcods@gmail.com
Bioactive Glass and Hydroxyapatite crystals exhibit pulpal biocompatibility, antibacterial property, osteogenic property and good bonding to tooth structure.
Bioactive Glass and Hydroxyapatite Crystals were found to be promising regenerative materials for pulpotomy in primary teeth.

\section{Abstract}

Aim: To clinically and radiographically evaluate the potential of bioactive glass and hydroxyapatite crystals as pulpotomy agents in primary molars. Methods: A total of fifty teeth were selected from 25 children (14 boys and 11 girls) aged 4 to 9 years, who had no medical condition that would contraindicate pulp therapy. Each child had at least two primary molars (first and/or second primary molar) requiring pulpotomy. A conventional pulpotomy procedure was performed on the selected teeth using bioactive glass and hydroxyapatite crystals. All molars were evaluated clinically and radiographically at regular intervals over 12 months. The results were subjected to statistical analysis using Fischer exact test. Results: One hundred percent clinical success and 84\% radiographic success was observed in both the groups at the end of the study period. Conclusions: The study concluded that both bioactive glass and hydroxyapatite crystals can be used as pulpotomy agents in primary molars.

Keywords: Bioactive Glass; Deciduous Teeth; Hydroxyapatite; Pulpotomy

Received: 30 October 2020

Accepted: 02 December 2020

Online First: 15 December 2020 


\section{INTRODUCTION}

Pediatric endodontics focuses on keeping the pulp of primary teeth vital until their physiological resorption in order to maintain the space between teeth, prevent detrimental tongue and speech habits, preserve esthetics, and maintain chewing function. ${ }^{1,2}$ Pulpotomy in primary dentition is a common therapeutic procedure which involves surgical amputation of the coronal infected portion of the vital pulp followed by the application of a medicament over the residual radicular pulp tissue to promote healing. Successful pulpotomy procedure depends not only on the correct diagnosis of the inflamed dental pulp, but also on the selection of an effective and biocompatible medicament. ${ }^{1,3}$ The ideal pulpotomy material should be bactericidal and harmless to cells and surrounding structures, promote healing of the pulp tissue and not interfere with the physiologic root resorption. ${ }^{5-6}$

Regeneration is a procedure to stimulate dentinal bridge or reparative dentin formation. There are various regenerative agents for pulpotomy such as calcium hydroxide, Mineral Trioxide Aggregate (MTA), bone morphogenic protein, enamel matrix derivative, lyophilized freeze dried platelet derived proteins and calcium enriched mixture. . $^{72}$

A material is said to be bioactive if it gives an appropriate biologic response and results in the formation of bond between material and the tissue. Bioactive glass is silicate based, containing calcium and phosphate. It is currently regarded as the most biocompatible material in the field of bone regeneration due to its bioactivity, osteoconductivity, osteoinductivity, hemostasis and its antibacterial property. ${ }^{13}$ Hydroxyapatite is the main inorganic component found in human hard tissues, i.e. tooth and bone. It is similar in crystallography and chemical composition to that of human hard tissue and has other properties like biocompatibility, bioactivity and steoconductivity. It is non-toxic and is non-inflammatory in nature. ${ }^{14}$

Both BAG and HA crystals are regenerative materials which have been extensively used for bone repair and bone grafting procedures, repair of mechanical bifurcation perforations, apical barrier formation, fillers for reinforcing restorative glass ionomer cement and composite resin. They have been effective as desensitizing agent post bleaching; for treating early carious lesions and as a remineralizing agent in toothpastes. Despite the ostensible abilities of hydroxyapatite crystals and bioactive glass to be osteoconductive, osteogenic and dentinogenic little research has been done on their application as pulpotomy agents. ${ }^{15}$ The null hypothesis was to test whether two materials with remineralizing properties (Bioactive glass and Hydroxyapatie crystals) would be successful as pulptomy agents in primary molars. Hence, the purpose of this clinical study was to assess the potential of bioactive glass and hydroxyapatite crystals as pulpotomy agents in primary molars.

\section{METHODS}

A randomized, split-mouth clinical trial was performed. Ethical clearance to conduct the study was obtained from the institutional review board of The Oxford Dental College, Hospital and Research Centre, Bangalore, Karnataka, India (Institutional Ethical Review Board: IERB), (315/2012-2013). Written informed consent was obtained from the patients and parents. The present prospective study was carried on normal, healthy and cooperative children from the patients attending the Department of Pedodontics and Preventive Dentistry of The Oxford Dental College, Hospital and Research Centre, Bommanhalli, Bangalore, India. The trial adhered to the Consolidated Standards of Reporting Trials (CONSORT) guidelines.

\section{Estimation of sample size}

The sample size was estimated based on assumption with $90 \%$ improvement. Hence, it is estimated with $5 \%$ significance level, $80 \%$ power and $20 \%$ allowable error of $80 \%$. The following formula provided the required sample size as follow:

$$
\mathrm{n}=\frac{\left[Z_{\alpha}+Z_{1-\beta}\right]^{2} \mathrm{pq}}{\mathrm{E}^{2}},
$$

where $\mathrm{n}=$ Estimated sample size, $\mathrm{Z}=1.96$ for $5 \%$ significance level, Z1- $\beta=0.841$ for $80 \%$ power, $\mathrm{p}=90, \mathrm{q}=10, \mathrm{E}=18$, by substituting this value $\mathrm{n}=22$, assuming $10 \%$ dropout, the sample size will be $n=22+3=25$. So, a total of 
fifty teeth were selected from 25 children (14 boys and 11 girls) aged 4 to 9 years, who had no medical condition that would contraindicate pulp therapy. Each child had at least two primary molars (first and/or second primary molar) requiring pulpotomy. The parents/guardians were informed about the condition of the child's dentition and the nature of the study was briefly explained. A brief history was recorded and the teeth were subjected to clinical examination and radiographic evaluation prior to the study. Participation in the study was voluntary and prior written informed consent was taken.

The clinical inclusion criteria selected for the study were as follows:

- Vital primary molars with probable carious pulp exposure

- Absence of spontaneous pain or persistent pain or nocturnal pain

- No clinical symptoms or evidence of pulp degeneration such as pain on percussion,

- No history of swelling or sinus tracts;

- Restorable tooth structure should be present

- Hemorrhage from the amputation site is bright red and easy to control

Radiographic inclusion criteria were as follows:

- Radiographic evidence of not more than one-third of physiologic root resorption

- Absence of furcal and/or periapical radiolucency

- Absence of radiographic evidence of internal or external root resorption

- Absence of pathologic root resorption

Exclusion criteria were as follow:

- Any of the above clinical or radiographic inclusion criteria are not met

- Remaining radicular tissue of the tooth was non-vital (suppuration/purulent necrosis)

- Hemostasis could not be achieved within 5 minutes by direct contact with a wet cotton pellet, prior to material placement.

In this split mouth study design, allocation of the primary molars to either bioactive glass (25 teeth) or hydroxyapatite crystals (25 teeth) group was randomized by the toss of a coin. In each child, one molar was treated with BAG and the other molar with HA crystals and divided in two groups; in Group I- pulpotomy was done using BAG and in Group II- pulpotomy was done using HA crystals.

A conventional pulpotomy procedure was performed on the selected teeth. Following administration of local anesthesia, rubber dam isolation was carried out. All dental caries and overhanging enamel was removed with a No. 330 high speed bur (Dentsply, USA) with water spray. Removal of all carious dentin was carried out with the use of a sterile No. 4 or 8 round slow speed bur (Dentsply, USA) and access to coronal pulp was gained and the entire roof of the pulp chamber was removed. A spoon excavator, large enough to extend across the entrance of the individual root canals was used to amputate the coronal pulp. The pulp stumps were cleanly excised until the root canal orifices could be seen, with no tags remaining on the pulpal floor. Gentle wash out of the debris was carried out with the water syringe. After completion of the amputation, hemorrhage was controlled using slightly moistened cotton pellets placed against the pulp stumps at the orifices of the root canals.

BAG (PerioglasR Bioactive Synthetic Bone Graft Particulate 45S5, Average particle size: 90700 microns, Unit size (Cup): $0.3 \mathrm{~cm}$, Novabone Perioglass Florida, USA) is usually available in either cup or syringe form. In the present study, according to the manufacturer instructions, 2-3 drops of sterile saline was added into the cup containing $0.5 \mathrm{cc}$ of $\mathrm{BAG}$ with the particle size measuring $90-700 \mu \mathrm{m}$. Once all the particles were wet with saline, the excess solution was blotted with sterile cotton. The mix was transferred to the root canal orifices using an amalgam carrier in order to standardize the quantity of the material placed. The material was condensed lightly using cylindrical condenser to confine the material placement at the root canal orifices. Bioactive glass was easy to place because of its cohesiveness.

HA crystals (G- Bone, SHAG 21, Synthetic Hydroxyapatite Granules, Average particle size: 0.4-0.9 mm, Hydroxyapatite crystal- Surgiwear G bone, Shahjahanpur, India) are available either in the syringe or cubes form. In the present study, the HA crystals dispensed in the syringe form 
measuring $1 \mathrm{cc}$ in quantity with the average particle size of $400-900 \mu \mathrm{m}$ was used. Due to its larger particle size, the material was grounded to small particles using a mortar and pestle.

After the placement of the regenerative agents, the pulp chamber was filled to about half its volume with a thick mixture of zinc oxide eugenol cement and access cavity was restored with miracle mix (GC Corporation, Tokyo, Japan). Following rubber dam removal, the occlusion was checked for high points using articulating paper. Immediate post-operative intraoral periapical radiographs were taken. In both the groups, final restoration with stainless steel crown (3M, ESPE, USA) was done within 1 week following the pulpotomy procedure.

The patients were recalled for clinical and radiographic evaluation after 1, 3, 6 and 12 month intervals. They were also instructed to report to the hospital on the development of any symptoms regarding the treated teeth, during the intervening 1 -year period.

The pulpotomized teeth were judged as clinically successful when they met the following criteria:

- Absence of pain, sensitivity or swelling.

- No tenderness to percussion

- Absence of an abscess or fistulation

- No pathologic mobility or premature exfoliation

Radiographic success criteria included the presence of a normal periodontal ligament space, absence of periapical/ furcal radiolucency, and absence of internal or external root resorption.

\section{Statistical Analysis}

Data was collected, tabulated and statistically analyzed. Data analysis was performed using SPSS (Statistical Package for the Social Sciences) Statistics for Windows, Version 18.0. Chicago: SPSS Inc. Fischer exact test was used for statistical analysis.

\section{RESULTS}

All 50 teeth were available till the end of the study (Table 1). One hundred percent success was observed clinically at all evaluation periods in both the groups (Table 2).

Table 1. Distribution of pulpotomized primary molars

\begin{tabular}{|c|c|c|c|}
\hline Primary molars & $\begin{array}{c}\text { Group I } \\
\text { (BAG) } \\
\mathrm{n}(\%)\end{array}$ & $\begin{array}{c}\text { Group II } \\
(\mathrm{HA}) \\
\mathrm{n}(\%)\end{array}$ & $\begin{array}{l}\text { Total } \\
\mathrm{N}(\%)\end{array}$ \\
\hline $\begin{array}{c}\text { Mandibular } 1^{\text {st }} \\
\text { molar }\end{array}$ & $15(60)$ & $16(64)$ & $31(62)$ \\
\hline $\begin{array}{c}\text { Mandibular } 2^{\text {nd }} \\
\text { molar }\end{array}$ & $5(20)$ & $6(24)$ & $11(22)$ \\
\hline $\begin{array}{l}\text { Maxillary } 1^{\text {st }} \\
\text { molar }\end{array}$ & $4(16)$ & $3(12)$ & 7(14) \\
\hline $\begin{array}{l}\text { Maxillary } 2^{\text {nd }} \\
\text { molar }\end{array}$ & 1(4) & 0 & $1(2)$ \\
\hline Total & $25(100)$ & $25(100)$ & $50(100)$ \\
\hline
\end{tabular}

Table 2. Clinical evaluation of both groups at 1,3,6 and 12 months

\begin{tabular}{lcccccccc}
\hline Evaluation Criteria & \multicolumn{3}{c}{ Period of evaluation (months) } & \multicolumn{5}{c}{ Period of evaluation (months) } \\
& 1 & 3 & 6 & 12 & 1 & 3 & 6 & 12 \\
& $\mathrm{n}(\%)$ & $\mathrm{n}(\%)$ & $\mathrm{n}(\%)$ & $\mathrm{n}(\%)$ & $\mathrm{n}(\%)$ & $\mathrm{n}(\%)$ & $\mathrm{n}(\%)$ & $\mathrm{n}(\%)$ \\
\hline $\begin{array}{l}\text { History of pain } \\
\text { Tenderness on }\end{array}$ & 0 & 0 & 0 & 0 & 0 & 0 & 0 & 0 \\
percussion & 0 & 0 & 0 & 0 & 0 & 0 & 0 & 0 \\
Swelling & 0 & 0 & 0 & 0 & 0 & 0 & 0 & 0 \\
Fistulation & 0 & 0 & 0 & 0 & 0 & 0 & 0 & 0 \\
Pathologic mobility & 0 & 0 & 0 & 0 & 0 & 0 & 0 & 0 \\
Premature exfoliation & 0 & 0 & 0 & 0 & 0 & 0 & 0 & 0 \\
\hline
\end{tabular}


Radiographically $100 \%$ success was seen at one month evaluation in both the groups (Table 3). At three month evaluation, periodontal ligament space widening was seen in two teeth $(8 \%)$ and furcal radiolucency was seen with regard to three teeth $(12 \%)$ in group I. In the Group II, two teeth $(8 \%)$ showed periodontal ligament space widening and one tooth (4\%) showed furcal radiolucency. At the six month of evaluation, furcal radiolucency was seen in four teeth $(16 \%)$ and external root resorption was observed in two teeth $(8 \%)$ in group I. In Group II, periodontal ligament space widening was seen in one tooth.

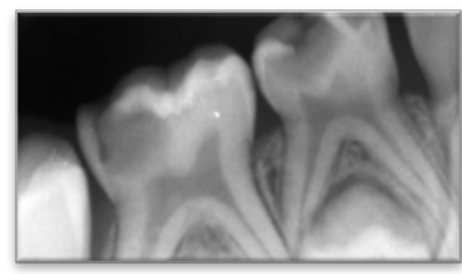

Figure 1. Preoperative intra oral periapical radiograph showing extensive carious lesions in mandibular primary molars, with more than two thirds of root length, and absence of furcal/ periapical radiolucency
At the end of study period, furcal radiolucency was seen in two teeth $(8 \%)$ and external root resorption in two teeth $(8 \%)$ in the Group I. In the Group II, periodontal ligament space widening in one tooth (4\%), furcal radiolucency in one tooth $(4 \%)$ and external root resorption in two teeth $(8 \%)$ was observed.

Overall, one hundred percent radiographic success was seen at one month follow up in both the groups. At the third month $80 \%$ success was observed in group I and group II revealed $88 \%$ success. At the sixth month follow up, in Group Iand Group II, 76\% and 84\% success was seen respectively. At twelfth month follow up, similar success of $84 \%$ was observed in both the groups; $\mathrm{p}>0.05$ was not significant. Figure 1 shows a representative picture of preoperative intra oral periapical radiograph showing extensive carious lesions in mandibular primary molars, with more than two thirds of root length, and absence of furcal/ periapical radiolucency. Figure 2, 3, 4, and 5 represents the follow-up radiographs of a pulpotomized $2^{\text {nd }}$ molar teeth after $1,3,6$, and 12 months, respectively.

Table 3. Radiographic evaluation of both groups at 1,3,6 and 12 months

\begin{tabular}{|c|c|c|c|c|c|c|c|c|c|}
\hline \multirow[t]{2}{*}{$\begin{array}{l}\text { RADIOGRAPHIC } \\
\text { CRITERIA }\end{array}$} & \multicolumn{4}{|c|}{ GROUP - I $\quad(n=25)$} & \multicolumn{5}{|c|}{ GROUP - II $(\mathrm{n}=25)$} \\
\hline & 1 month & 3month & 6month & 12 month & 1 month & 3month & Gmonth & 12 month & $\begin{array}{c}\mathrm{p} \\
\text { value }\end{array}$ \\
\hline $\begin{array}{l}\text { Periodontal } \\
\text { ligament space } \\
\text { widening }\end{array}$ & $0(0 \%)$ & $2(8 \%)$ & $0(\%)$ & $0(0 \%)$ & $0(0 \%)$ & $2(8 \%)$ & $1(4 \%)$ & $1(4 \%)$ & 0.25 \\
\hline Furcal radiolucency & $0(0 \%)$ & $3(12 \%)$ & $4(16 \%)$ & $2(8 \%)$ & $0(0 \%)$ & $1(4 \%)$ & $3(12 \%)$ & $1(4 \%)$ & 0.30 \\
\hline $\begin{array}{l}\text { Periapical } \\
\text { radiolucency }\end{array}$ & $0(0 \%)$ & $0(0 \%)$ & $0(0 \%)$ & $0(0 \%)$ & $0(0 \%)$ & $0(0 \%)$ & $0(0 \%)$ & $0(0 \%)$ & 1.0 \\
\hline $\begin{array}{l}\text { External root } \\
\text { resorption }\end{array}$ & $0(0 \%)$ & $0(0 \%)$ & $2(8 \%)$ & $2(8 \%)$ & $0(0 \%)$ & $0(0 \%)$ & $0(0 \%)$ & $2(8 \%)$ & 0.50 \\
\hline $\begin{array}{l}\text { Internal root } \\
\text { resorption }\end{array}$ & $0(0 \%)$ & $0(0 \%)$ & $0(0 \%)$ & $0(0 \%)$ & $0(0 \%)$ & $0(0 \%)$ & $0(0 \%)$ & $0(0 \%)$ & 1.0 \\
\hline
\end{tabular}




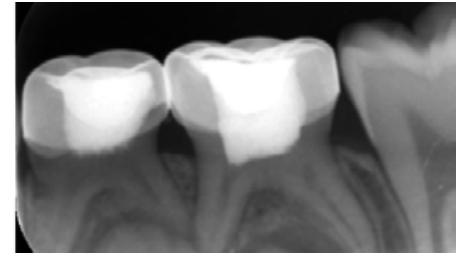

Figure 2. 1-month follow-up periapical radiograph showing the pulpotomized teeth

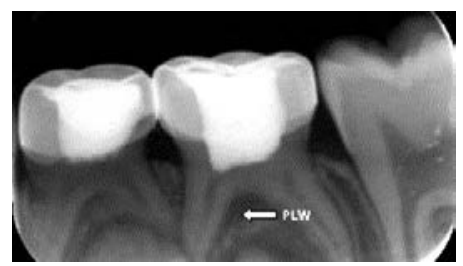

Figure 3. 3-month follow-up periapical radiograph suggesting widening of periodontal ligament (PLW) in $2^{\text {nd }}$ molar

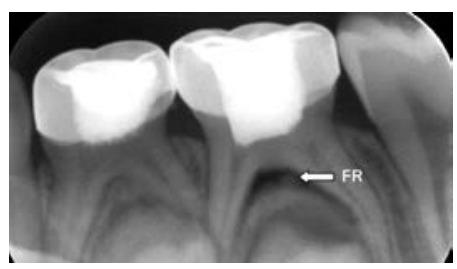

Figure 4. 6-month follow-up periapical radiograph suggesting of furcal radiolucency (FR) in $2^{\text {nd }}$ molar

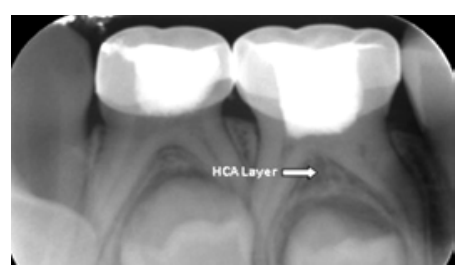

Figure 5. 12-month follow-up periapical radiograph showing radiopacity in $2^{\text {nd }}$ molar

\section{DISCUSSION}

Recent research into endodontic materials has focused on what is called the "biological era". With greater understanding of the pulp biology, pathophysiology and its power of healing, the emphasis has shifted to the regeneration of pulp. Several agents such as calcium hydroxide, MTA, bone morphogenic protein have been successfully used as regenerative pulpotomy agents. ${ }^{8,12,16}$ Though these materials have been used extensively, they have their inherent drawbacks. Calcium hydroxide does not adhere to dentin, cause internal root resorption and dissolves over a period of time. On the other hand, MTA has long setting time and tends to cause discoloration of dental tissues.

Amongst various regenerative agents, BAG and HA crystals have been assessed due to their biocompatibility, bioinductivity, antibacterial property, osteogenicity, and the ability to stimulate hard tissue formation in the field of medicine and dentistry. ${ }^{17}$ Studies on their application in pediatric dentistry is limited because of the economic, commercial reasons and also taking into account the time of survival of the primary tooth in the oral cavity. ${ }^{18,19}$ Therefore, in the present study, BAG and HA crystals were selected for use as regenerative pulpotomy agents in primary molars.

In order to make comparison of the two materials possible, the selected children had to have at least two primary molars requiring pulpotomy. For ethical reasons, every child had one primary molar each, treated with $\mathrm{BAG}$ and HA crystals. Hence, no child was withheld from the benefits of either of the two pulpotomy agents. It also ensured direct comparison of both the medicaments within the same mouth.

Beyond the pulpotomy material properties, the biological sealing after pulpotomy is fundamental for the pulp treatment success. ${ }^{18}$ Therefore, in this study all the pulpotomized teeth were initially restored using zinc oxide eugenol cement as a sub base immediately following application of both the regenerative agents due to its lack of mechanical strength, followed by miracle mix (GC Corporation: Tokyo, Japan) because of its good compressive strength and direct bond to tooth structure. ${ }^{17,20}$

However, it is imperative that a permanent restoration be placed as soon as possible for the overall success of the treatment. In order to achieve an enhanced seal and to compensate for potential marginal leakage of the restoration, all the molars were restored with stainless steel crowns (3M ESPE, USA) within one week post operatively. Stainless steel crowns (SSCs) were most suitable since all these primary molars had sufficient longevity with considerable time for exfoliation to occur. SSCs are always considered superior to multisurface restorations in primary molars. Failure in other types of permanent restorations include fractures, ditches and secondary caries, that require re-treatment 
whereas, with stainless steel crowns there could only be a need for re-cementation of crowns. ${ }^{21,22}$

The treatment outcome of any study is largely determined by the criteria used to evaluate whether, any treatment procedure has been "successful". In the present study, pulpotomy was regarded as a success in the absence of clinical signs and symptoms such as pain, swelling, fistula and/or radiographic evidence including periapical or furcal radiolucency and external or internal root resorption. ${ }^{12,22}$

Throughout the entire evaluation period none of the primary molars treated with BAG showed any clinical signs and symptoms. BAG has shown to provide enhanced seal over the vital pulp as it does not deteriorate, disintegrate and resorb with time. ${ }^{23}$ The mechanism underlying the binding of BAG to collagen fibers may be the result of a rapid surface reaction that takes place on the glass when exposed to physiological solutions. There will be rapid exchange and release of ions that attack the silica glass network which leads to formation of silanols at the glass solution interface. The continuous condensation of silanols will form $\mathrm{SiO}_{2}$ rich gel layer. The ions released from the BAG to the surface through the $\mathrm{SiO}_{2}$ rich layer binds with the reactive groups of the collagen structure resulting in the formation of HCA layer (Hydroxyapatite Carbonate Layer). As dentin matrix comprises of $90 \%$ collagen fibers, the adherence of the reacted surface of the bioactive glass particle to underlying tissue forms stronger chemical bond. ${ }^{24,25}$ This bonding provides matrix for mineralization and hermetic seal to prevent microleakage. This could be one of the reasons for clinical success observed in group I, wherein BAG was used as a pulpotomy agent.

BAG also has an antibacterial potential due to its ability to raise the $\mathrm{pH}$ in an aqueous suspension which is not well tolerated by bacterial cells. $^{26}$ Silica levels are also reported to be responsible for the antibacterial nature of the bioactive glass. ${ }^{27}$

All the teeth in group I were evaluated as radiographically successful at one month postoperative evaluation. This result is in accordance with earlier in-vivo studies. ${ }^{22,28}$
Radiographically, at three months in Group I (BAG), two primary molars (8\%) showed periodontal ligament space widening and furcal radiolucency was observed in three additional primary molars $(12 \%)$. This could be due to a protective inflammatory response of the body to BAG which is a foreign material. ${ }^{23,29}$ This initial inflammatory response may also be due to the high alkalinity at the site of application. When BAG is exposed to physiological solutions or body fluids, it rapidly releases ions such as $\mathrm{Na}^{+}$, $\mathrm{K}^{+}, \mathrm{Mg}^{+2}$ and $\mathrm{Ca}^{+2}$. There will be cation exchange processes which will increase the concentration of hydroxyl ions at the $\mathrm{BAG} /$ solution interface, thereby raising the $\mathrm{pH}$ to around 10.5.24,25,30

In fact, the inflammatory process continued to be evident even at 6 months, the periodontal ligament space widening seen with one of the primary molars progressed to involve the furcation area. External root resorption seen in two teeth could have also been due to the inflammatory reaction of tissue to BAG.

In group II (HA), all teeth were clinically successful throughout the evaluation period. Hydroxyapatite crystals are more biocompatible as their stoichiometry is similar to tooth structure. ${ }^{31}$ They are compatible with fibroblasts, osteoclasts, osteoblasts and periodontal ligament cells. Apart from two primary molars with periodontal ligament space widening, furcal radiolucency was observed in one primary molar $(4 \%)$ at three months evaluation. In the present study, the initially larger sized crystals of HA were ground to fine particle size in order to improve its handling characteristics and for convenient placement of the material at the application site. Higashi et al. ${ }^{32}$ reported that tissue inflammatory response was seen more with usage of smaller particle size in comparison to larger particle size. Similarly, the placement of smaller sized HA crystals could have triggered an inflammatory response that manifested as furcal radiolucency in three primary molars at the end of 6 months evaluation. These results were in accordance with a previous study. ${ }^{33}$

At the twelfht month of evaluation, external root resorption was visible in two of the furcally involved teeth. It could be a result of smaller particle size and irregular shape of the hydroxyapatite crystals. The other reason could be 
due to inflammation that could not be diagnosed clinically or due to individual immunological response of patients to the regenerative agent. ${ }^{34}$

As per the clinical criteria used in the present study, all the fifty pulpotomized primary molars treated in both the groups were evaluated as successful. In both groups, furcation radiolucency and external root resorption were observed to occur more frequently in first primary molars, probably due to their smaller crown size and highly situated pulpal horns. This is in accordance with that of previous studies, which showed a higher prevalence of pulpotomy failures in first primary molars. ${ }^{35-36}$

During the initial period of evaluation, a higher percentage of radiographic success was seen with teeth treated with HA. However, at the end of 12 months, with bioactive glass, healing and regeneration of tissue resulted in success $(84 \%)$ that was comparable with HA crystals. The statistical analysis showed $\mathrm{p}>0.05$ which was not significant.

Based on the observations of this study, both BAG and HA crystals appear to be successful pulpotomy agents in primary molars. Presently one of the factors limiting the routine use of these materials is the high cost of these materials. Since they are difficult to store, it is recommended to discard any material remaining after its usage. Moreover, in primary molars the quantity of the material used is minimal. Both materials are considered to be technique sensitive. Therefore, economic usage of both materials is not feasible. With growing concerns regarding the use of formocresol, BAG and HA crystals can be the preferred choice for pulpotomy agents in primary molars due to their biocompatibility and regenerative properties. Longitudinal studies for more than a year including histologic evaluation of these teeth following exfoliation should be done to study the pulpal response towards these agents. Their effect on development and eruption of the underlying succedaneous tooth is also a potential topic for research.

Given their high success rate, BAG and HA can be considered as suitable regenerative agents for pulpotomy procedure in primary teeth.

\section{CONCLUSIONS}

One hundred percent clinical success was observed throughout the evaluation period in both the groups. The radiographic evaluation revealed $100 \%, 80 \%, 76 \%$ and $84 \%$ success at 1 , 3, 6, and 12 months respectively with BAG as pulpotomy agent. In Group II, radiographically $100 \%$ and $88 \%$ success were seen at 1 and 3 months respectively. A similar success of $84 \%$ was observed at both 6 and 12 months radiographic evaluation with HA crystals. There was no statistically significant difference between the two materials on both clinical and radiographic evaluation at the end of the study period.

This observation advocates further clinical, radiographic and histological studies with longer follow- up till the period of tooth exfoliation to ascertain the efficacy of these novel regenerative pulpotomy agents.

\section{REFERENCES}

1. Coll JA, Seale NS, Vargas K, Marghalani AA, Al Shamali S, Graham L. Primary Tooth vital pulp therapy: a systematic review and metaanalysis. Pediatr Dent 2017;39:16-123

2. Oliveira TM, Moretti AB, Sakai VT, Lourenço Neto N, Santos CF, Machado MA, et al. Clinical, radiographic and histologic analysis of the effects of pulp capping materials used in pulpotomies of human primary teeth. Eur Arch Paediatr Dent 2013;14:65-71

3. Ohkura N, Edanami N, Takeuchi R, Tohma A, Ohkura M, Yoshiba, et al. Effects of pulpotomy using mineral trioxide aggregate on prostaglandin transporter and receptors in rat molars. Sci Rep 2017;7:6870-6872

4. Sonmez D, Sari S, Çetinbas T. A comparison of four pulpotomy techniques in primary molars: a long-term follow-up. J Endod 2008;34:950-955

5. Moretti AB, Sakai VT, Oliveira TM, Fornetti AP, Santos CF, Machado MA, et al. The effectiveness of MTA, calcium hydroxide and formocresol for pulpotomies in primary teeth. Int Endod J 2008;41:547-555

6. Sakai VT, Moretti AB, Oliveira TM, Fornetti AP, Santos CF, Machado MA, et al. Pulpotomy of human primary molars with MTA and Portland 
cement: a randomised controlled trial. Brt Dent J 2009;207:128-129

7. Ratnakumari N, Thomas B. A histopathological comparision of pulpal response to Chitra-CPC and formocresol used as pulpotomy agents in primary teeth: clinical trial. Int J Clin Pediatr Dent 2012;5:6-13

8. Ranly DM. pulpotomy therapy in primary teeth: new modalities for old rationales. Pediatr Dent 1994;16:403-409

9. Torabinejad M, Chivian N. Clinical applications of mineral trioxide aggregate. J Endod 1999;25:197-205

10. Bengtson A, Bengtson N, Bengtson C, Pinheiro S, Guedes A. pulpotomy in human deciduous teeth and bone morphogenic protein. Rev Clin Pesq Odontol 2008;4:129-136

11. Mohamed A, Maha MF, Wahba N, Meligy O, Sabbarini J. Comparison of pulpal response following pulpotomy procedure using enamel matrix derivative versus formocresol in primary dentition. Calcif Tissue Int 2004;75:243-252

12. Kalaskar RR, Damle SG. Compartaive evaluation of lyophilized freeze dried platelet derived preparation with calcium hydroxide as pulpotomy agents in primary molars. Pediatr Dent 2000;4:140-146

13. McDonald RE, Avery DR, Dean JA. Dentistry for the child and adolescent, $8^{\text {th }}$ ed. St. Louis, Mosby; 2004;389-412

14. Farooq I, Imran Z, Farooq U, Leghari A. Bioactive Glass: A material for the future. World J Dent 2012;3:199-201

15. Hench L. Chronology of bioactive glass development and clinical applications. New J Glass Cer 2013;3:67-73

16. Hargreaves K, Cohen S. Pathways of the pulp. 10th ed. St Louis: Elseiver; 2011. p 822-831

17. Saltzman B, Sigal M, Clokie C, Rukavina J, Titley K, Kulkarni GV. Assessment of a novel alternative to conventional formocresol-zinc oxide eugenol pulpotomy for the treatment of pulpally involved human primary teeth, diode laser and mineral trioxide aggregate pulpotomy. Int J Paediatr Dent 2005;15:437-447

18. Junqueira MA, Cunha NNO, Caixeta FF, Marques NCT, Oliveira TM, Moretti ABDS, Cosme-Silva L, Sakai VT. Clinical, Radiographic and Histological Evaluation of Primary Teeth pulpotomy Using MTA And Ferric Sulfate. Braz Dent J 2018;29:159-165

19. Smail-Faugeron V, Courson F, Durieux P, Muller-Bolla M, Glenny AM, Fron Chabouis H. Pulp treatment for extensive decay in primary teeth. Cochrane Database Syst Rev 2014;6:CD003220

20. Croll TP, Killian CM. Zinc oxide eugenol pulpotomy and stainless steel crown restoration of a primary molar. Quintessence Int 1992;23:383-388

21. Randal RC, Vrijhoef MMA, Wilson NHF. Efficacy of preformed metal crowns vs amalgam restoration in deciduous molars. $\mathrm{Br}$ Dent J 1986;2:177-183

22. Agamy HA, Barky NS, Mounir MMF, Avery DR. Comparison of mineral trioxide aggregate and formocresol as pulp capping agents in pulpotomized primary teeth. Pediatr Dent 2004; 26:302-309

23. Jabbarifar E, Razavi SM, Ahmadi N. Histopathologic responses of dog's dental pulp to mineral trioxide aggregate, bio active glass, formocresol, hydroxyapatite. Dent Res J 2007;4:83-87

24. Hench L, Greenspan D. Interactions between Bioactive Glass and Collagen: A Review and New Perspectives. J Australian Ceramic Society 2013;49:1-40

25. Aza PN, De Aza AH, Pena P and De Aza S. Bioactive glasses and glass-ceramic. Bol Soc Esp Ceram V 2007;46:45-55

26. Eberhard J, Reimers N, Dommisch H, Hacker J, Freitag S, Acil Y, Albers h, Jopsen S. The effect of the topical administration of bioactive glass on inflammatory markers of human experimental gingivitis. Biomaterials 2005;26:1545-1551

27. Zehnder M, Waltimo T, Sener B, Soderling E. Dentin enhances the effectiveness of bioactive glass S53P4 against a strain of Enterococcus faecalis. Oral Surg Oral Med Oral Pathol Oral Radiol Endod 2006;101:530-535

28. Airen P, Shigli A, Airen B. Comparative evaluation of formocresol and mineral trioxide aggregate in pulpotomized primary molars -2 year follow up. J Clin Pediatr Dent 2012;37:143147

29. Salako N, Joseph B, Ritwik P, Salonen J, John $\mathrm{P}$, and Junaid TA. Comparison of bioactive glass, 
mineral trioxide aggregate, ferric sulfate, and formocresol as pulpotomy agents in rat molar. Dent Traumatol 2003;19:314-320

30. Humagain M, Nayak DG, Uppoor AS. A clinical evaluation of bioactive glass particulate in the treatment of mandibular class II furcation defects. Braz J Oral Sci 2007;6:1450-1456

31. Markovic D, Vanja P, Mirjana L, Zorana N. Radiologic assessment of apex formation following use of hydroxyapatite. Acta Veternaria (Beograd) 2007;57:275-287.

32. Higashi T, Okamoto $H$. Influence of particle size of calcium phosphate ceramics as a capping agent on the formation of a hard tissue barrier in amputated dental pulp. J Endod 1996;22:281-283

33. Adlakha VK, Chandana P, Joshi JL, Thomas AM, Singh N. A comparative evaluation of hydroxyapatite crystals and glutaldehyde as agents for pulpotomy in deciduous molars. Int $\mathrm{J}$ Clin Pediatr Dent 2009;2:13-22

34. Frankle G, Kaufan A, Ashenazi M. Clinical and radiographic outcomes of pulpotomized primary molars treated with white or grey mineral trioxide aggregate and ferric sulfate- long term follow up. J Clin Pediatr Dent 2012;37:137-141

35. Holan H, Eidelman E, Odont, Fucks AB. Long term evaluation of pulpotomy in primary molars using mineral trioxide aggregate or formocresol. Pediatr Dent 2005;27:129-136

36. Subramaniam P, Konde S, Mathew S, Sugnani S. Mineral trioxide aggregate as pulp capping agent for primary teeth pulpotomy: 2 year follow up study. J Clin Pediatr Dent 2009;33:311-314

\section{How to cite this article:}

Neeraja Govindaraj, Kinjal Shah Virani, Priya Subramaniam, Megha Gupta. Evaluation of bioactive glass and hydroxyapatite crystals as pulpotomy agents in primary molars: A clinical study. Contemp Pediatr Dent 2020:1(1):42-51.

\section{Declarations}

Acknowledgements: Not applicable.

Conflict of Interest Statement: The authors disclose no potential conflicts of interest.

Ethics Statement: Ethical clearance to conduct the study was obtained from the institutional review board of The Oxford Dental College, Hospital and Research Centre, Bangalore, Karnataka, India (Institutional Ethical Review Board: IERB), (315/2012-2013).

Informed Consent: Written informed consent was obtained from the patients and parents.

Author contributions: Conception and design: All Authors; Acquisition of data: KSV; Interpretation of data: NG, KSV, PV; Drafting article: NG; Revision artice: $M G, N G$; Final approval: All Authors

Funding: This work is not finantiated.

Data Availability: The data used to support the findings of this study can be made available upon request to the corresponding author.

Peer-review: Externally double-blinded peer-reviewed. 